\title{
Enhanced Cardiac CaMKII Oxidation and CaMKII-Dependent SR Ca Leak in Patients with Sleep-Disordered Breathing
}

\author{
Michael Arzt 1,+, Marzena A. Drzymalski ${ }^{1,+}$, Sarah Ripfel ${ }^{1}$, Sebastian Meindl ${ }^{1}$, Alexander Biedermann ${ }^{1}$, \\ Melanie Durczok ${ }^{1}$, Karoline Keller ${ }^{1}$, Julian Mustroph ${ }^{1}$, Sylvia Katz ${ }^{2,3}$, Maria Tafelmeier ${ }^{1}$, Simon Lebek ${ }^{1}{ }^{1}$, \\ Bernhard Flörchinger ${ }^{4}$, Daniele Camboni ${ }^{4}$, Sigrid Wittmann ${ }^{5}$, Johannes Backs ${ }^{2,3}$, Christof Schmid ${ }^{4}$, \\ Lars S. Maier ${ }^{1}\left(\mathbb{D}\right.$ and Stefan Wagner ${ }^{1, *(\mathbb{D})}$
}

check for updates

Citation: Arzt, M.; Drzymalski, M.A.; Ripfel, S.; Meindl, S.; Biedermann, A.; Durczok, M.; Keller, K.; Mustroph, J.; Katz, S.; Tafelmeier, M.; et al. Enhanced Cardiac CaMKII Oxidation and CaMKII-Dependent SR Ca Leak in Patients with Sleep-Disordered Breathing. Antioxidants 2022, 11, 331. https://doi.org/10.3390/ antiox11020331

Academic Editor: Nazha Hamdani

Received: 3 December 2021

Accepted: 7 February 2022

Published: 8 February 2022

Publisher's Note: MDPI stays neutral with regard to jurisdictional claims in published maps and institutional affiliations.

Copyright: (C) 2022 by the authors. Licensee MDPI, Basel, Switzerland. This article is an open access article distributed under the terms and conditions of the Creative Commons Attribution (CC BY) license (https:// creativecommons.org/licenses/by/ $4.0 /)$.
1 Department of Internal Medicine II, University Hospital Regensburg, 93053 Regensburg, Germany; michael.arzt@ukr.de (M.A.); Marzena.Drzymalski@gmail.com (M.A.D.); sarah.ripfel@klinik.uni-regensburg.de (S.R.); tt_basti@yahoo.de (S.M.); alexanderbiedermann@gmx.net (A.B.); melanie.durczok@ukr.de (M.D.); karoline.keller92@outlook.de (K.K.); julian.mustroph@ukr.de (J.M.); maria.tafelmeier@klinik.uni-regensburg.de (M.T.); simon.lebek@ukr.de (S.L.); lars.maier@ukr.de (L.S.M.)

2 Department of Molecular Cardiology and Epigenetics, University of Heidelberg, 69120 Heidelberg, Germany; Sylvia.Katz@med.uni-heidelberg.de (S.K.); johannes.backs@med.uni-heidelberg.de (J.B.)

3 German Centre for Cardiovascular Research (DZHK), Partner Site Heidelberg/Mannheim, 69120 Heidelberg, Germany

4 Department of Cardiothoracic Surgery, University Hospital Regensburg, 93053 Regensburg, Germany; Bernhard.Floerchinger@ukr.de (B.F.); daniele.camboni@klinik.uni-regensburg.de (D.C.); Christof.Schmid@ukr.de (C.S.)

5 Department of Anesthesiology, University Hospital Regensburg, 93053 Regensburg, Germany; sigrid.wittmann@ukr.de

* Correspondence: stefan.wagner@ukr.de

+ These authors contributed equally to this work.

Abstract: Background: Sleep-disordered breathing (SDB) is associated with increased oxidant generation. Oxidized Ca/calmodulin kinase II (CaMKII) can contribute to atrial arrhythmias by the stimulation of sarcoplasmic reticulum Ca release events, i.e., Ca sparks. Methods: We prospectively enrolled 39 patients undergoing cardiac surgery to screen for SDB and collected right atrial appendage biopsies. Results: SDB was diagnosed in 14 patients (36\%). SDB patients had significantly increased levels of oxidized and activated CaMKII (assessed by Western blotting/specific pulldown). Moreover, SDB patients showed a significant increase in Ca spark frequency (CaSpF measured by confocal microscopy) compared with control subjects. CaSpF was $3.58 \pm 0.75$ (SDB) vs. $2.49 \pm 0.84$ (no SDB) $1 / 100 \mu \mathrm{m}^{-1} \mathrm{~s}^{-1}(p<0.05)$. In linear multivariable regression models, SDB severity was independently associated with increased $\mathrm{CaSpF}$ (B [95\%CI]: 0.05 [0.03; 0.07], $p<0.001)$ after adjusting for important comorbidities. Interestingly, $30 \mathrm{~min}$ exposure to the CaMKII inhibitor autocamtide2 related autoinhibitory peptide normalized the increased $\mathrm{CaSpF}$ and eliminated the association between SDB and CaSpF (B [95\%CI]: 0.01 [-0.1; 0.03], $p=0.387$ ). Conclusions: Patients with SDB have increased CaMKII oxidation/activation and increased CaMKII-dependent CaSpF in the atrial myocardium, independent of major clinical confounders, which may be a novel target for treatment of atrial arrhythmias in SDB.

Keywords: calcium-calmodulin-dependent protein kinase type II; sleep apnea; atrial fibrillation; sarcoplasmic reticulum Ca leak

\section{Introduction}

Atrial fibrillation (AF) is the most common cardiac arrhythmia, affecting approximately 4.5 million people in the European Union and 2.3 million people in North America [1-3]. The incidence of AF is expected to increase dramatically by 2050, as the general population ages and becomes more obese [4]. AF is associated with substantially increased 
morbidity and mortality, owing to the concomitant risk of embolic stroke and worsening heart failure (HF) [1]. At the level of the atrial cardiomyocyte, electrical, structural and Ca-handling remodeling have been suggested to contribute to the induction and perpetuation of AF [5,6]. Previous evidence suggests that spontaneous sarcoplasmic reticulum (SR) Ca release events (i.e., Ca sparks) are a major trigger for AF [7-9]. In particular, increased activity of $\mathrm{Ca}$ /calmodulin kinase II (CaMKII) and consequent hyperphosphorylation of the SR Ca release channel RyR2 has been identified in the right atrial myocardium of patients with AF $[8,9]$.

Sleep-disordered breathing (SDB) is a widespread disease of high socio-economic importance owing to its clinical corollaries [6]. Important consequences of SDB are atrial arrhythmias including AF [10], stroke [11,12] and hypertension [13]. SDB has also been associated with recurrence of AF after electrical cardioversion [14] or ablation of AF [15]. The method of choice for treatment of SDB is continuous positive airway (CPAP) therapy, but there is increasing evidence that CPAP therapy does not reduce the burden of AF [16], as previously thought. Unfortunately, the pathophysiological mechanisms of arrhythmogenesis in SDB are poorly understood. Recently we have shown that patients with SDB have increased amounts of reactive oxygen species (ROS) in the atrial myocardium [17]. Oxidative stress is induced in SDB by intermittent hypoxemia with cyclical changes of hypoxemia with reoxygenation [18,19]. Interestingly, oxidation of CaMKII is an important mechanism of CaMKII activation [20], and oxidized CaMKII has been shown to contribute to AF in a murine model [21]. Moreover, recently we have shown an enhanced activity of CaMKII that contributes to pro-arrhythmic activity in atrial myocardium of cardiovascular patients with SDB [17].

Therefore, we tested the hypothesis that patients with SDB have more oxidized CaMKII in the atrium, and that CaMKII-dependent Ca sparks are more frequent in patients with SDB. This has therapeutic relevance, since CaMKII inhibitors are already in preclinical development [22].

\section{Materials and Methods}

\subsection{Study Design}

Patients undergoing elective coronary artery bypass graft (CABG) surgery were prospectively included for tissue donation (Figure 1). Exclusion criteria were known sleep apnea and CPAP therapy. Functional measurements of atrial cardiomyocytes and protein analysis of atrial biopsies were performed by blinded investigators.

\subsection{Study Approval}

This research was approved by the ethics committee and performed in accordance with the Declaration of Helsinki (first released in 1964, most recent revision 2013). Patients provided written consent prior to tissue donation.

\subsection{Assessment of SDB by Polygraphy}

Nasal flow, pulse oximetry and thoracal breathing effort were measured using the ApneaLink device (ResMed, Sydney, Australia) that has been validated in several studies for screening of SDB [23-28]. Comparing ApneaLink (using automatic scoring) to the gold standard polysomnography (PSG) in patients without known heart disease, studies have reported a sensitivity of 73-94\% and a specificity of $85-95 \%$ using an AHI cut-off value of $15 / \mathrm{h}$ [29]. As described previously [29,30], apnea was defined as a $\geq 80 \%$ decrease in airflow for $\geq 10 \mathrm{~s}$; hypopnea was defined as a decrease in airflow by $\geq 50-80 \%$ versus baseline for $\geq 10 \mathrm{~s}$; desaturation was defined as a $\geq 4 \%$ decrease in oxygen saturation; the oxygen desaturation index $(4 \%)$ is the number of desaturations per hour. SDB was defined as an apnea-hypopnea index (AHI) $\geq 15$ per hour. 


\subsection{Confocal Ca Measurements}

Ca sparks were assessed by confocal microscopy using the Ca dye fluo-4 acetoxymethylester. Isolated myocytes were loaded with $10 \mu \mathrm{mol} / \mathrm{L}$ fluo-4 acetoxymethylester (Molecular Probes) for $12 \mathrm{~min}$ at room temperature and mounted on an inverted laser scanning confocal microscope (Zeiss LSM 7) for measurement.

\subsection{Statistical Analysis}

Continuous data are expressed as mean \pm standard deviation (SD). Please refer to the online supplement for detailed methods.

\section{2 patients undergoing elective CABG surgery with or without heart valve replacement and}

- assessment of SDB in the preoperative night

- right atrial appendage-biopsies during CABG surgery

- isolation and measurements of atrial cardiac myocytes

\section{Reasons for exclusion: \\ $\mathrm{n}=3$ known sleep apnea and CPAP-therapy}

\section{$n=39$}

included in analysis and stratified according to SDB status

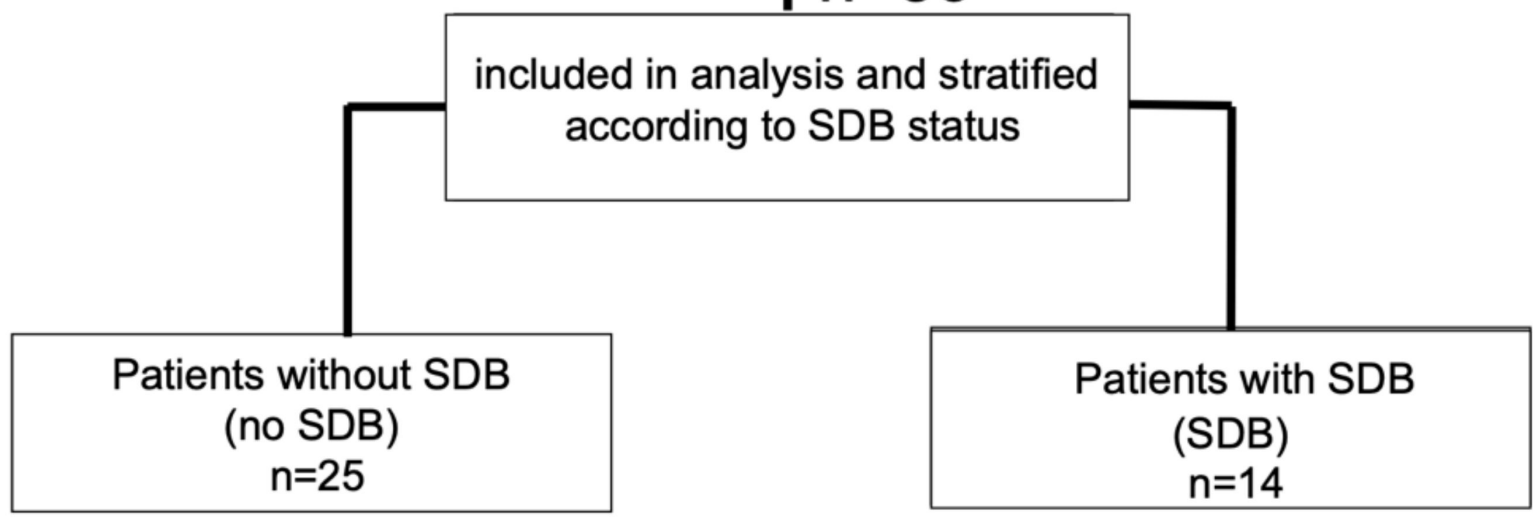

Figure 1. Patient flow chart. After screening, 39 patients were included in the analysis. Abbreviations: $\mathrm{CABG}$, coronary artery bypass graft; $\mathrm{CPAP}$, continuous positive airway pressure; SDB, sleep-disordered breathing.

\section{Results}

\subsection{Patients}

Thirty-nine patients with coronary heart disease undergoing elective CABG surgery fulfilled the inclusion and exclusion criteria for this analysis (Figure 1).

Moderate to severe SDB (AHI $\geq 15 / \mathrm{h}$ ) was diagnosed in $36 \%$ of patients. Comparing the baseline characteristics of both groups, patients with SDB had a significantly lower left ventricular ejection fraction (LVEF, $p=0.004$ ) and a higher rate of left atrial dilation $(p=0.011$, Table 1$)$. Interestingly, SDB patients showed a significantly greater overall prevalence of AF (paroxysmal and permanent combined, Table 1). AF was present in $43 \%$ of SDB patients vs. $12 \%$ in the group without SDB ( $p=0.028$, Table 1$)$. A history of stroke was significantly more common in SDB patients compared to those without SDB 
$(p=0.028$, Table 1$)$. The remaining variables were not significantly different between cohorts. However, age, the need for additional surgical valve replacement and NT-proBNP levels were numerically higher in the SDB group. In contrast, ACE inhibitor/angiotensin receptor blocker (ACEi/ARB) therapy was less frequent in the SDB group (Table 1). Gender representation in the SDB group was exclusively male.

Table 1. Baseline characteristics.

\begin{tabular}{|c|c|c|c|}
\hline & $\begin{array}{c}\text { No SDB } \\
(n=25)\end{array}$ & $\begin{array}{c}\text { SDB } \\
(n=14)\end{array}$ & $p$ Value \\
\hline Age (years), mean $\pm S D$ & $67 \pm 10$ & $70 \pm 9$ & 0.386 \\
\hline Male gender, $\mathrm{n}(\%)$ & $20(80)$ & $14(100)$ & 0.073 \\
\hline Body mass index $\left(\mathrm{kg} / \mathrm{m}^{2}\right)$, mean $\pm \mathrm{SD}$ & $28.8 \pm 4.5$ & $28.9 \pm 4.5$ & 0.962 \\
\hline CABG and valve replacement, n (\%) & $5(20)$ & $5(36)$ & 0.281 \\
\hline \multicolumn{4}{|l|}{ Cardiovascular risk factors } \\
\hline Hypertension, n (\%) & $21(84)$ & $12(86)$ & 0.887 \\
\hline Diabetes mellitus, n (\%) & $6(25)$ & $5(36)$ & 0.482 \\
\hline Previous Smoker, n (\%) * & $10(67)$ & $6(75)$ & 0.679 \\
\hline Hypercholesterolemia, n (\%) & $16(64)$ & $8(57)$ & 0.673 \\
\hline Atrial fibrillation, $\mathrm{n}(\%)$ & $3(12)$ & $6(43)$ & 0.028 \\
\hline Paroxysmal AF & $1(4)$ & $3(21)$ & 0.085 \\
\hline Persistent AF & $2(8)$ & $3(21)$ & 0.229 \\
\hline Previous stroke $n(\%)$ & $3(12)$ & $6(42.9)$ & 0.028 \\
\hline \multicolumn{4}{|l|}{ Heart and renal function } \\
\hline Heart Failure, n (\%) & $15(60)$ & $10(71)$ & 0.475 \\
\hline NT-pro BNP (pg/mL), median (IQR) & $\begin{array}{c}226 \\
(85,1128)\end{array}$ & $\begin{array}{c}1024 \\
(414,4575)\end{array}$ & 0.129 \\
\hline $\operatorname{LVEF}(\%)$, mean $\pm \mathrm{SD} * *$ & $55 \pm 13$ & $37 \pm 11$ & 0.004 \\
\hline $\mathrm{GFR}(\mathrm{mL} / \mathrm{min})$, mean $\pm \mathrm{SD}$ & $77 \pm 16$ & $69 \pm 28$ & 0.262 \\
\hline Dilated left atrium, $\mathrm{n}(\%) * * *$ & $3(33)$ & $9(90)$ & 0.011 \\
\hline \multicolumn{4}{|l|}{ Medication at admission } \\
\hline ACE-inhibitors and/or AT1 blockers, n (\%) & $22(88)$ & $9(64)$ & 0.079 \\
\hline Betablockers & $19(76)$ & $10(71)$ & 0.750 \\
\hline Statins, $\mathrm{n}(\%)$ & $20(80)$ & $8(57)$ & 0.128 \\
\hline Digitalis, $\mathrm{n}(\%)$ & $0(0)$ & $1(7)$ & 0.176 \\
\hline Aldosterone receptor antagonists, n (\%) & $3(12)$ & $2(14)$ & 0.838 \\
\hline Thiazid diuretics, $\mathrm{n}(\%)$ & $6(24)$ & $7(50)$ & 0.098 \\
\hline Loop diuretics, n (\%) & $6(24)$ & $6(43)$ & 0.221 \\
\hline
\end{tabular}

IQR indicates interquartile range, which lies between the 25th and the 75th percentiles; sleep-disordered breathing is defined as an apnea-hypopnea index $\geq 15 / \mathrm{h}$. CABG, coronary artery bypass grafting; NT-pro BNP, Nterminal pro-brain natriuretic peptide; LVEF, left ventricular ejection fraction; GFR, glomerular filtration rate; ACE, angiotensin-converting enzyme; AT1, angiotensin receptor. Divergent patient numbers from total $\mathrm{n}=39$ : * current and previous smoker, $\mathrm{n}=23$ ( $\mathrm{n}(\mathrm{AHI}<15)=15 ; \mathrm{n}(\mathrm{AHI} \geq 15=8) ;{ }^{* *} \mathrm{LVEF}, \mathrm{n}=20(\mathrm{n}(\mathrm{AHI}<15)=18$; $\mathrm{n}(\mathrm{AHI} \geq 15=11) ;{ }^{* * *}$ dilated left atrium, $\mathrm{n}=19(\mathrm{n}(\mathrm{AHI}<15)=9 ; \mathrm{n}(\mathrm{AHI} \geq 15=10)$.

By definition, patients in the SDB group had moderate to severe SDB, with a significantly higher oxygen desaturation index $(4 \%)(p<0.001)$, indicating intermittent hypoxemia (Table 2). In the SDB group, the majority of apneas was obstructive in nature, and CheyneStokes respiration was present in only $9 \%$ of total recording time (Table 2).

\subsection{Increased CaMKII Oxidation and Activity in Patients with SDB}

Intermittent hypoxemia results in ROS generation. To investigate if CaMKII is more oxidized in SDB patients, which would lead to increased CaMKII activity, we measured the level of oxidized CaMKII in homogenates from right atrium (RA) biopsies (Figure 2A,B). Compared to patients without SDB, ox-CaMKII levels (relative to total CaMKII expression) were significantly increased in biopsies from patients with SDB (Figure 2A,B). The oxCaMKII/CaMKII ratio doubled from $0.74 \pm 0.36$ (no SDB, $\mathrm{n}=15$ ) to $1.51 \pm 0.76$ (SDB, $\mathrm{n}=8$, $p<0.05$ ). Interestingly, there was a significant positive correlation between the severity of SDB (AHI) and CaMKII oxidation (B [95\%CI]: 0.043 [0.021; 0.065], $\mathrm{n}=23, \mathrm{R}^{2}=0.447, p<0.05$, 
Figure 2C, Table S1 in online supplement). Moreover, CaMKII oxidation also significantly correlated with oxygen desaturation index (ODI), another measure of intermittent hypoxia. In contrast, parameters of sustained hypoxia such as minimal nocturnal oxygen saturation and percentage of time below $90 \%$ saturation were not found more frequently in SDB patients (Table 2) and were not associated with the extent of CaMKII oxidation (Table S1 in online supplement).

Table 2. Nocturnal polygraphy.

\begin{tabular}{lccc}
\hline & $\begin{array}{c}\text { No SDB } \\
(\boldsymbol{n}=\mathbf{2 5})\end{array}$ & $\begin{array}{c}\text { SDB } \\
(\boldsymbol{n}=\mathbf{1 4})\end{array}$ & $p$ Value \\
\hline Total recording time, min & $548 \pm 91$ & $516 \pm 117$ & 0.336 \\
Apnea-hypopnea index, /h & $6 \pm 3$ & $26 \pm 13$ & $<0.001$ \\
Apnea index, /h & $2 \pm 2$ & $12 \pm 13$ & 0.012 \\
Obstructive apnea index, /h & $1 \pm 1$ & $5 \pm 4$ & $<0.001$ \\
Oxygen desaturation index (4\%), /h & $6.1 \pm 3.3$ & $24.1 \pm 11.2$ & $<0.001$ \\
Minimal oxygen saturation, \% & $79.1 \pm 8.7$ & $76.0 \pm 5.9$ & 0.249 \\
Oxygen saturation below 90\%, \% of TRT & $16 \pm 20$ & $24 \pm 20$ & 0.220 \\
Cheyne-Stokes respiration, \%/TRT & $1 \pm 3$ & $9 \pm 15$ & 0.020 \\
\hline
\end{tabular}

Data are mean \pm SD. Sleep-disordered breathing (SDB) is defined as an apnea-hypopnea index $\geq 15 / h$. Abbreviations; TRT: total recording time.

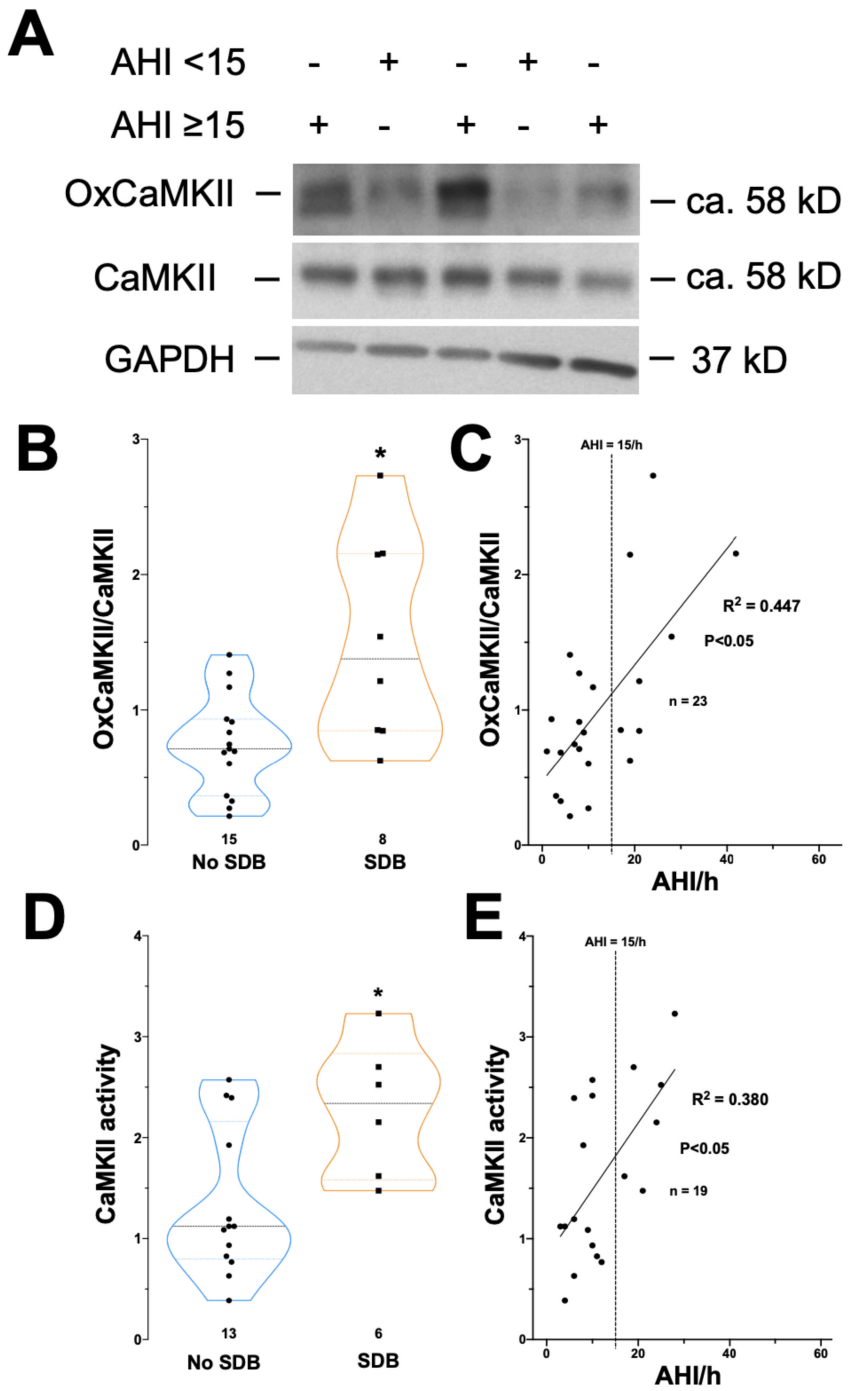

Figure 2. Increased oxidation and activity of CaMKII in patients with SDB. Original Western 
blot (A) and mean densitometric data (B) investigating the expression of oxidized CaMKII relative to CaMKII expression. Compared to control patients (no SDB), there was a significant increase in the level of oxidized CaMKII (oxCaMKII/CaMKII) in patients with SDB. (C) Scatter plot for the correlation of AHI and oxCaMKII/CaMKII. Linear regression analysis is shown as line plot. Mean densitometric data (D) for the assessment of CaMKII activity by using specific HDAC4 pulldown. There was a significant increase in CaMKII activity in patients with SDB. (E) Scatter plot for the correlation of $\mathrm{AHI}$ and CaMKII-activity. Linear regression analysis is shown as line plot. ${ }^{*} p<0.05$ vs. no SDB ( $t$-test).

In accordance, the activity of CaMKII (measured as described previously [31]) was significantly enhanced in RA biopsies of patients with SDB (Figure 2D). CaMKII activity increased from $1.34 \pm 0.74$ (no SDB, $\mathrm{n}=13$ ) to $2.28 \pm 0.67$ (SDB, $\mathrm{n}=6, p<0.05$ ). There was also a significant correlation between CaMKII activity and AHI (linear regression analysis, B [95\%CI]: 0.066 [0.023; 0.109], $\mathrm{n}=19, \mathrm{R}^{2}=0.38, p<0.05$, Figure 2E).

\subsection{Ca Spark Frequency Is Increased in Patients with SDB}

To investigate whether the SDB-dependent increase in CaMKII activity may be accompanied by disturbed intracellular Ca handling, Ca sparks were measured by confocal microscopy in atrial cardiomyocytes isolated as previously described [9,32]. Figure 3 shows confocal line scans of cardiomyocytes from two representative individual patients from both groups. The frequency of diastolic Ca release events, i.e., Ca spark frequency (CaSpF), was significantly increased in patients with SDB (Figure 3B). CaSpF (in $1 / 100 \mu \mathrm{m}^{-1} \mathrm{~s}^{-1}$ ) increased from $2.49 \pm 0.84$ (no SDB, $\mathrm{n}=25$ ) to $3.58 \pm 0.75$ (SDB, $\mathrm{n}=14, p<0.05$, Figure 3B).

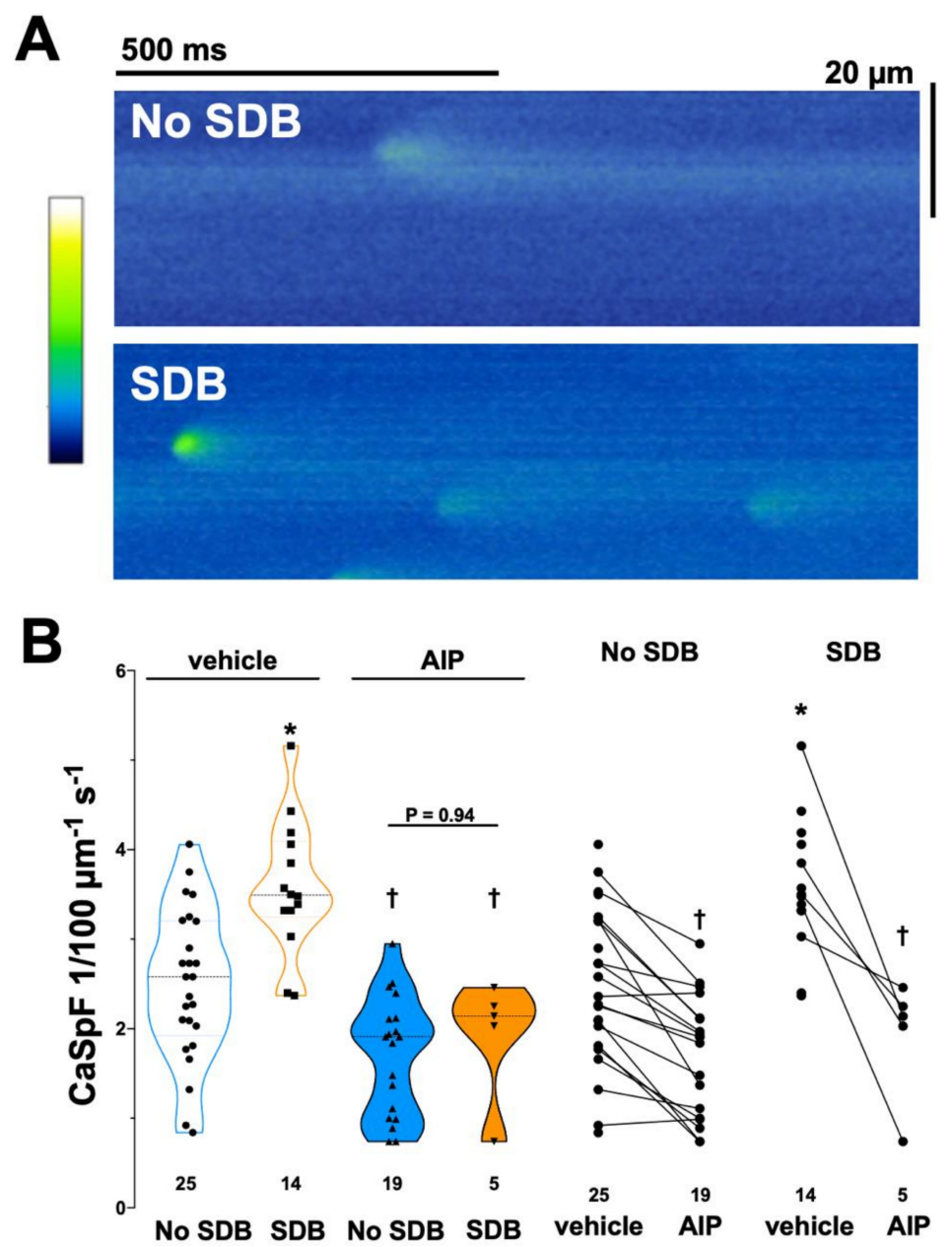

Figure 3. Patients with SDB showed increased Ca spark frequency. (A) Original confocal line scans 
of Fluo-4 loaded atrial cardiomyocytes isolated from patients without SDB and with SDB. The measured fluorescence intensity was color coded according to the calibration bar. (B) Mean data for diastolic Ca spark frequency ( $\mathrm{CaSpF}$ ) is shown as violin plot (left panel) or spaghetti plot (right panel). Compared to control patients (no SDB), the frequency of Ca sparks was significantly enhanced in patients with SDB. Importantly, this increase in CaSpF could be blocked with the selective CaMKII inhibitor autocamtide-2 related autoinhibitory peptide (AIP). ${ }^{*} p<0.05$ vs. no SDB,$+p<0.05$ vs. vehicle (two-way RM ANOVA, mixed effects model).

Moreover, CaSpF correlated significantly with the severity of SDB (AHI), as assessed by linear correlation $\left(\mathrm{R}^{2}=0.44, \mathrm{~B}[95 \% \mathrm{CI}]: 0.052\right.$ [0.032; 0.071], $\mathrm{n}=39, p<0.001$; Table 3, and Figure S1 in online supplement). In accordance with CaMKII oxidation, CaSpF also significantly correlated with ODI, but not with minimal nocturnal oxygen saturation nor percentage of time below $90 \%$ saturation (Table 3). We have shown previously that stimulation of the angiotensin 1 receptor results in increased CaSpF in a CaMKII-dependent fashion [25]. Interestingly, univariate linear regression analysis indicate that ACEi/ARB therapy was indeed significantly associated with a decreased CaSpF (Table 3) but not with decreased CaMKII oxidation (Table S1 in online supplement).

Table 3. Linear regression analysis for CaSpF.

\begin{tabular}{|c|c|c|c|c|c|c|}
\hline \multirow[b]{3}{*}{ Variable } & \multirow{2}{*}{\multicolumn{2}{|c|}{$\begin{array}{c}\text { Simple Linear Regression } \\
\text { Analysis }\end{array}$}} & \multicolumn{4}{|c|}{ Multiple Linear Regression Analysis } \\
\hline & & & \multirow{2}{*}{$\begin{array}{c}\text { Model I } \\
\text { B (95\% CI) }\end{array}$} & \multirow{2}{*}{$\frac{\mathrm{R}^{2} 0.505}{p \text { Value }}$} & \multirow{2}{*}{$\begin{array}{c}\text { Model II } \\
\text { B }(95 \% \text { CI })\end{array}$} & \multirow{2}{*}{$\frac{\mathrm{R}^{2} 0.585}{p \text { Value }}$} \\
\hline & B $(95 \%$ CI $)$ & $p$ Value & & & & \\
\hline AHI, /h & $0.052(0.032 ; 0.071)$ & $<0.001$ & $0.048(0.028 ; 0.068)$ & $<0.001$ & $0.040(0.017 ; 0.062)$ & $<0.001$ \\
\hline ODI, /h & $0.059(0.038 ; 0.080)$ & $<0.001$ & & & & \\
\hline $\mathrm{MinO}_{2}, \%$ & $\begin{array}{c}-0.021 \\
(-0.061 ; 0.019)\end{array}$ & 0.288 & & & & \\
\hline $\begin{array}{c}\mathrm{O}_{2} \text { below } 90 \%, \% \text { of } \\
\text { TRT }\end{array}$ & $0.009(-0.007 ; 0.024)$ & 0.255 & & & & \\
\hline Age/10, years & $0.04(-0.291 ; 0.370)$ & 0.810 & $-0.002(-0.257 ; 0.253)$ & 0.985 & $0.025(-0.255 ; 0.306)$ & 0.855 \\
\hline Male gender & $1.031(0.153 ; 1.909)$ & 0.023 & $0.591(-0.140 ; 1.322)$ & 0.110 & $0.703(-0.049 ; 1.456)$ & 0.066 \\
\hline $\begin{array}{l}\text { Body-mass index, } \\
\qquad \mathrm{kg} / \mathrm{m}^{2}\end{array}$ & $0.029(-0.042 ; 0.100)$ & 0.417 & $0.038(-0.17 ; 0.093)$ & 0.170 & $0.057(-0.001 ; 0.115)$ & 0.053 \\
\hline $\begin{array}{c}\text { NT-pro BNP/1000, } \\
\text { pg/mL }\end{array}$ & $0.047(-0.019 ; 0.114)$ & 0.160 & & & $0.034(-0.018 ; 0.087)$ & 0.193 \\
\hline Diabetes & $0.188(-0.554 ; 0.790)$ & 0.724 & & & $0.161(-0.367 ; 0.690)$ & 0.538 \\
\hline $\mathrm{AF}$ & $0.169(-0.550 ; 0.889)$ & 0.636 & & & $\begin{array}{c}-0.262 \\
(-0.873 ; 0.349)\end{array}$ & 0.388 \\
\hline ACEi/ARB therapy & $\begin{array}{c}-0.799 \\
(-1.532 ;-0.065)\end{array}$ & 0.034 & & & $\begin{array}{c}-0.591 \\
(-1.276 ; 0.094)\end{array}$ & 0.088 \\
\hline $\begin{array}{l}\text { Beta blocker } \\
\text { therapy }\end{array}$ & $\begin{array}{c}-0.081 \\
(-0.802 ; 0.640)\end{array}$ & 0.821 & & & & \\
\hline Valve replacement & $\begin{array}{c}-0.036 \\
(-0.757 ; 0.686)\end{array}$ & 0.921 & & & & \\
\hline LVEF $<50 \%$ & $0.362(-0.437 ; 1.160)$ & 0.361 & & & & \\
\hline Dilated left atrium & $0.345(0.726 ; 1.417)$ & 0.506 & & & & \\
\hline & $\begin{array}{l}\text { Model I accou } \\
\text { diabetes, } \mathrm{AF} \mathrm{a} \\
\text { index, } \mathrm{MinO}_{2} \\
\text { time, NT-pro } \\
\text { fraction, ACEi }\end{array}$ & $\begin{array}{l}\text { for age, } 1 \\
\text { ACEi/AR } \\
\text { inimal oxy } \\
\text { : N-termir } \\
\text { RB: ACE i }\end{array}$ & $\begin{array}{l}\text { le gender and BMI. Mode } \\
\text { herapy. Abbreviations: A } \\
\text { n saturation, } \mathrm{O}_{2} \text { below } 90 \\
\text { pro-brain natriuretic pept } \\
\text { bitor/angiotensin-recepto }\end{array}$ & $\begin{array}{l}\text { I accounts } \\
\text { apnea-hy } \\
\text { oxygen sa } \\
\text { AF: atrial } \\
\text { locker ther }\end{array}$ & $\begin{array}{l}\text { r age, male gender, BMI } \\
\text { pnea index, ODI: oxyger } \\
\text { ration below 90\%, TRT: } t \\
\text { rillation, LVEF: left vent }\end{array}$ & $\begin{array}{l}\text { NT-pro BNI } \\
\text { lesaturatior } \\
\text { al recording } \\
\text { ular ejectior }\end{array}$ \\
\hline
\end{tabular}

\subsection{CaMKII Inhibition Reduces SDB-Dependent Ca Spark Frequency}

To test if enhanced SDB-dependent CaMKII activity is responsible for the increase in $\mathrm{CaSpF}$, we also exposed isolated atrial cardiomyocytes to the selective CaMKII inhibitor AIP ( $2 \mu \mathrm{mol} / \mathrm{L}, 30 \mathrm{~min}$ ). In the presence of AIP, CaSpF was significantly reduced in both groups (Figure 3B, spaghetti plots), masking the difference between patients with and without SDB. Similarly, linear regression analysis revealed a loss of correlation of AHI and CaSpF in 
the presence of $\mathrm{AIP}\left(\mathrm{R}^{2}=0.04, p=0.355 ; \mathrm{B}[\mathrm{CI}]: 0.01\right.$ [ $\left.\left.-0.01 ; 0.03\right], p=0.355\right)$. In accordance, AIP blocked the SDB-dependent enhancement of diastolic SR Ca leak (Figure S2A, online supplement). Interestingly, AIP significantly increased the amplitude of individual $\mathrm{Ca}$ sparks in SDB patients, indicating that SR Ca content may increase with CaMKII inhibition (Figure S2B, online supplement).

\subsection{SR Ca Content Was Reduced in Patients with SDB}

To find out if enhanced SR Ca leak in SDB patients could be linked to reduced SR Ca content, which would impair atrial contractility, we rapidly exposed atrial cardiomyocytes to caffeine. Figure $4 \mathrm{~A}$ illustrates representative line scan images of caffeine-induced $\mathrm{Ca}$ transients $\left(\Delta \mathrm{F} / \mathrm{F}_{0}\right)$ from two representative individual patients. The caffeine-transient amplitude was significantly reduced in atrial myocytes of patients with SDB (Figure 4B). $\Delta \mathrm{F} / \mathrm{F}_{0}$ was reduced from $8.03 \pm 2.39($ no $\mathrm{SDB}, \mathrm{n}=14)$ to $4.23 \pm 1.60(\mathrm{SDB}, \mathrm{n}=7, p<0.05$, Figure $4 \mathrm{~B})$. In addition, there was a significant negative correlation between $\mathrm{AHI}$ and caffeine-transient amplitude $\left(\mathrm{R}^{2}=0.307, \mathrm{~B}[95 \% \mathrm{CI}]:-1.04[-1.79 ;-0.29], \mathrm{n}=21, p<0.05\right.$, Table 4, Figure S1B, online supplement). Conversely, acute inhibition of CaMKII with AIP tended to increase the caffeine-transient amplitude in SDB patients (Figure 4B). Consistently, linear regression analysis revealed a loss of correlation of $\mathrm{AHI}$ and $\mathrm{CaSpF}$ in the presence of $\operatorname{AIP}\left(\mathrm{R}^{2}=0.001 ; p=0.896 ; \mathrm{B}(\mathrm{CI}) ; 0.02(-0.29 ; 0.26), \mathrm{n}=17, p=0.896\right)$.

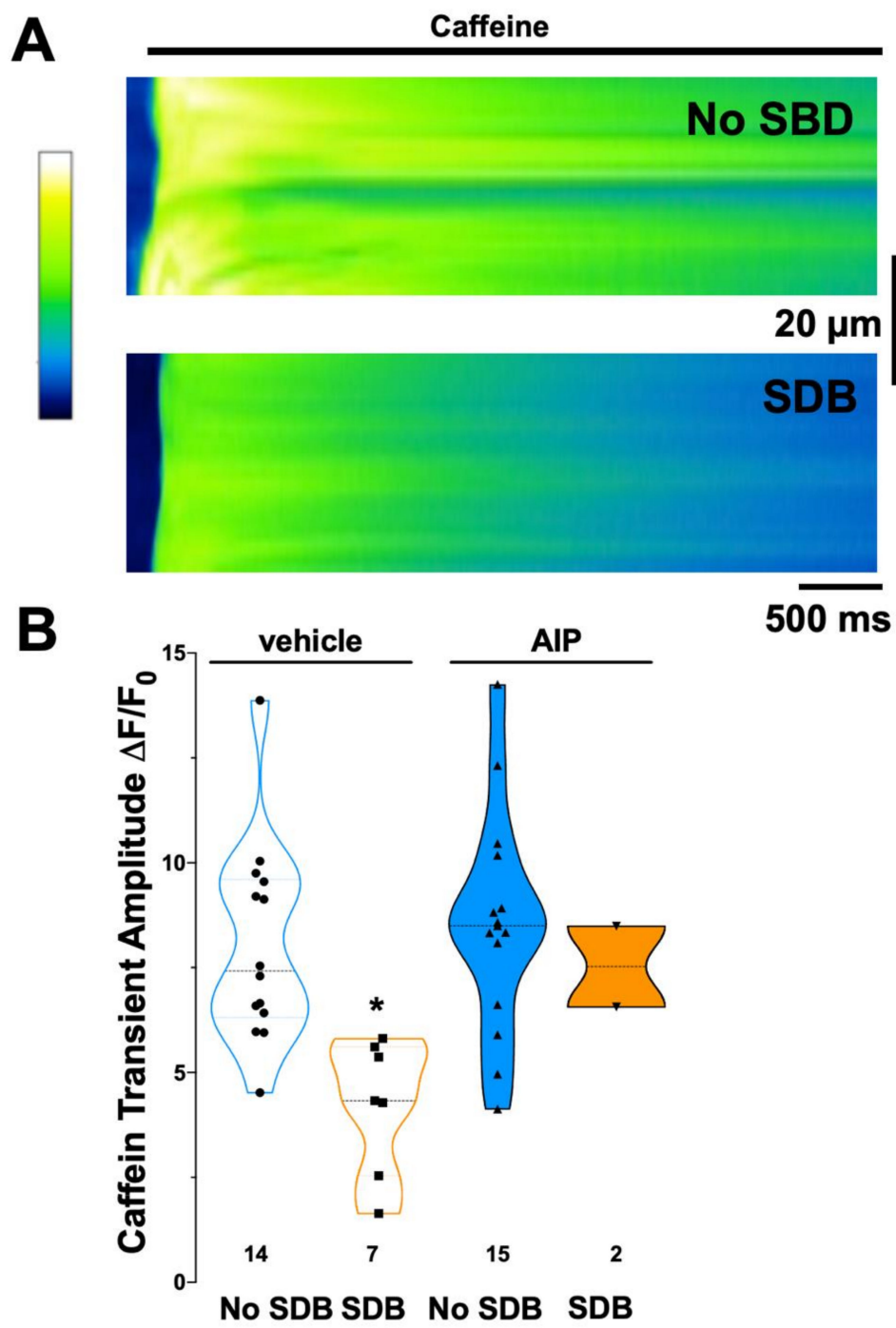

Figure 4. Patients with SDB display reduced SR Ca content. (A) Original confocal line scans of Fluo-4 
loaded atrial cardiomyocytes rapidly exposed to caffeine $(10 \mathrm{mmol} / \mathrm{L})$. The measured fluorescence intensity was color coded according to the calibration bar. (B) Mean data for caffeine-induced Ca transient amplitude $\Delta \mathrm{F} / \mathrm{F} 0$ as a measure of SR Ca content. Compared to control patients (no SDB), the caffeine-transient amplitude was significantly lower in patients with SDB. Interestingly, the presence of AIP did not alter the caffeine-transient amplitude in patients without SDB. In contrast, in patients with SDB, there was a trend towards an increase in caffeine-transient amplitude in the presence of AIP. ${ }^{*} p<0.05$ vs. no SDB (two-way RM ANOVA, mixed effects model).

Table 4. Linear regression analyses for caffeine-transient amplitude (measure of SR Ca load).

\begin{tabular}{|c|c|c|c|c|c|c|}
\hline \multirow[b]{3}{*}{ Variable } & \multirow{2}{*}{\multicolumn{2}{|c|}{$\begin{array}{c}\text { Simple Linear Regression } \\
\text { Analysis }\end{array}$}} & \multicolumn{4}{|c|}{ Multiple Linear Regression Analysis } \\
\hline & & & \multirow{2}{*}{$\frac{\text { Model I }}{\text { B }(95 \% \text { CI })}$} & \multirow{2}{*}{$\begin{array}{l}\mathrm{R}^{2} 0.343 \\
p \text { Value }\end{array}$} & \multirow{2}{*}{$\begin{array}{c}\text { Model II } \\
\text { B }(95 \% \text { CI })\end{array}$} & \multirow{2}{*}{$\begin{array}{l}\mathrm{R}^{2} 0.436 \\
p \text { Value }\end{array}$} \\
\hline & B $(95 \%$ CI $)$ & $p$ Value & & & & \\
\hline AHI, /h & $\begin{array}{c}-1.042 \\
(-1.794 ;-0.291)\end{array}$ & 0.009 & $\begin{array}{c}-1.048(-1.952 \\
-0.144)\end{array}$ & 0.026 & $\begin{array}{c}-0.123 \\
(-0.241 ;-0.005)\end{array}$ & 0.043 \\
\hline ODI, /h & $\begin{array}{c}-0.133 \\
(-0.213 ;-0.053)\end{array}$ & 0.003 & & & & \\
\hline $\mathrm{MinO}_{2}, \%$ & $0.075(-0.061 ; 0.211)$ & 0.264 & & & & \\
\hline $\begin{array}{c}\mathrm{O}_{2} \text { below } 90 \%, \% \text { of } \\
\text { TRT }\end{array}$ & $\begin{array}{c}-0.045 \\
(-0.097 ; 0.008)\end{array}$ & 0.090 & & & & \\
\hline Age/10, years & $\begin{array}{c}-0.252 \\
(-1.723 ; 1.219)\end{array}$ & 0.724 & $-0.588(-2.088 ; 0.911)$ & 0.418 & $0.317(-2.284 ; 2.918)$ & 0.795 \\
\hline Male gender & $\begin{array}{c}-1.915 \\
(-4.764 ; 0.934)\end{array}$ & 0.176 & $-0.503(-3.568 ; 2.562)$ & 0.732 & $0.585(-4.114 ; 5.285)$ & 0.791 \\
\hline $\begin{array}{l}\text { Body-mass index, } \\
\mathrm{kg} / \mathrm{m}^{2}\end{array}$ & $\begin{array}{c}-0.010 \\
(-0.306 ; 0.286)\end{array}$ & 0.945 & $0.054(-0.255 ; 0.364)$ & 0.715 & $0.112(-0.296 ; 0.519)$ & 0.562 \\
\hline $\begin{array}{c}\text { NT-pro BNP/1000, } \\
\text { pg/mL }\end{array}$ & $\begin{array}{c}-0.141 \\
(-0.352 ; 0.071)\end{array}$ & 0.181 & & & $\begin{array}{c}-0.112 \\
(-0.406 ; 0.183)\end{array}$ & 0.426 \\
\hline Diabetes & $0.201(-2.507 ; 2.908)$ & 0.878 & & & $0.808(-2.305 ; 3.921)$ & 0.582 \\
\hline $\mathrm{AF}$ & $\begin{array}{c}-0.883 \\
(-3.662 ; 1.896)\end{array}$ & 0.515 & & & $\begin{array}{c}-1.716 \\
(-6.904 ; 3.474)\end{array}$ & 0.485 \\
\hline ACEi/ARB therapy & $0.254(-2.430 ; 2.937)$ & 0.846 & & & $\begin{array}{c}-1.313 \\
(-4.922 ; 2.297)\end{array}$ & 0.444 \\
\hline $\begin{array}{l}\text { Beta blocker } \\
\text { therapy }\end{array}$ & $\begin{array}{c}-2.071 \\
(-4.577 ; 0.436)\end{array}$ & 0.100 & & & & \\
\hline Valve replacement & $\begin{array}{c}-2.125 \\
(-4.754 ; 0.503)\end{array}$ & 0.107 & & & & \\
\hline LVEF $<50 \%$ & $\begin{array}{c}-1.585 \\
(-3.654 ; 0.483)\end{array}$ & 0.123 & & & & \\
\hline Dilated left atrium & $\begin{array}{c}-2.342 \\
(-5.508 ; 0.824)\end{array}$ & 0.130 & & & & \\
\hline
\end{tabular}

Model I accounts for age, male gender and BMI. Model II accounts for age, male gender, BMI, NT-pro BNP, diabetes, AF and ACEi/ARB therapy. Abbreviations: AHI: apnea-hypopnea index, ODI: oxygen desaturation index, $\mathrm{MinO}_{2}$ : minimal oxygen saturation, $\mathrm{O}_{2}$ below $90 \%$ : oxygen saturation below $90 \%$, TRT: total recording time, NT-pro BNP: N-terminal pro-brain natriuretic peptide, AF: atrial fibrillation, LVEF: left ventricular ejection fraction, ACEi/ARB: ACE inhibitor/angiotensin-receptor blocker therapy.

\subsection{SDB-Dependent Atrial Remodeling Was Also Observed in Patients with Sinus Rhythm}

To exclude the possibility that pre-existing AF (irrespective of cause) and not the severity of SDB underlies the observed increase in CaMKII activity and changes in intracellular Ca handling, we repeated the analysis after omitting all patients with either pre-existing paroxysmal or persistent AF (Figure S3, online supplement). Notably, after exclusion of patients with AF, the SDB-dependent enhancement of CaMKII oxidation and activity was completely maintained (Figure S3A,B, online supplement). Moreover, the SDB-dependent increase in $\mathrm{CaSpF}$ and the reduction in caffeine-transient amplitude were also not affected by the removal of patients with AF from the analysis set (Figure S3C,D, online supplement).

To further investigate potential clinical confounders, we performed multivariate linear regression with CaMKII oxidation (Table S1 in online supplement), CaSpF (Table 3) and 
caffeine-induced Ca transients (Table 4). Model I accounts for age, gender and BMI, and model II additionally accounts for NT-pro BNP, diabetes, AF and ACEi/ARB therapy.

In these models, AHI remained the only significant predictor of CaMKII oxidation, $\mathrm{CaSpF}$ and caffeine-induced Ca transients. Similarly to AHI, the obstructive apnea index $(\mathrm{OAI})$, the central apnea index $(\mathrm{CAI})$ and the frequency of Cheyne-Stokes respiration were associated with increased $\mathrm{CaSpF}$, independent of known potential confounders (model I, OAI: (B [95\%CI]): 0.118 [0.028; 0.209], $p=0.012$, Table S2, online supplement; CAI: (B [95\%CI]): 0.06 [0.023; 0.096], $p=0.002$, Table S3, online supplement, Cheyne-Stokes respiration: (B [95\%CI]): 0.291 [ $-0.180 ; 0.600], p=0.064$, Table S4, online supplement).

\section{Discussion}

The major novel finding of this study is the observation that patients with SDB have increased atrial CaMKII-dependent SR-Ca leak and decreased SR-Ca content, which can be reversed by acute CaMKII inhibition. This SDB-dependent CaMKII-related SR Ca leak correlates with the severity of SDB and is independent of important confounding clinical factors such as preexisting $\mathrm{AF}, \mathrm{HF}$ or diabetes.

\subsection{SDB Results in Increased CaMKII Oxidation}

Increased activity of CaMKII has been causally linked to contractile dysfunction and arrhythmias in patients with AF [8,9] and HF [34-37]. However, the mechanisms of activation remain insufficiently understood. In addition to Ca-calmodulin-dependent stimulation, oxidation of CaMKII is an important alternative CaMKII activation pathway [20], which is critical for the regulation of intracellular $\mathrm{Na}$ and $\mathrm{Ca}$ homeostasis [38-40]. The relevance of oxidized CaMKII for atrial arrhythmias has been confirmed in a murine model of AF [21]. Interestingly, SDB is characterized by intermittent arterial hypoxemia with cyclical changes of hypoxemia with reoxygenation. As a result, the production of ROS is increased $[18,19]$. Recently we have shown that patients with SDB have increased amounts of reactive oxygen species (ROS) in atrial myocardium [17], which was in accordance murine SDB models (chronic intermittent hypoxia), but also patients [17,19,41,42]. Here we report increased CaMKII oxidation and CaMKII activation in atrial myocardium of patients with SDB. Moreover, the magnitude of CaMKII oxidation correlates significantly with the severity of the SDB (measured by AHI), which suggests that CaMKII oxidation may be a major CaMKII activation pathway in SDB. Thus, inhibition of CaMKII oxidation may represent an even more specific target for the treatment or prevention of arrhythmias in patients with SDB. This is particularly important since ATP-competitive CaMKII inhibitors with high CaMKII selectivity and good bioavailability, but nonspecific inhibition of CaMKII activity regardless of their activation pathway, are currently being developed [22].

\subsection{SDB Patients Show Increased CaMKII-Dependent SR Ca Leak and Reduced SR Ca Content}

Increased CaMKII-dependent SR Ca leak is a major mechanism of CaMKII-dependent arrhythmias, and contractile dysfunction $[35,36,43]$ is associated with the development of HF and can be detected in patients with AF [8,9,44-47]. CaMKII has been shown to phosphorylate the SR Ca release channel RyR2, resulting in increased diastolic open probability [48]. As a result, the frequency of spontaneous diastolic RyR2 openings (i.e., Ca sparks) is elevated, leading to increased diastolic SR Ca leak [49]. It is known that diastolic Ca release events activate the subsarcolemmal $\mathrm{Na} / \mathrm{Ca}$ exchanger to export $\mathrm{Ca}$ out of the cell in exchange for $\mathrm{Na}$ [8]. This net transport of cations into the cell $\left(3 \mathrm{Na}^{+}\right.$in exchange for $1 \mathrm{Ca}^{2+}$ ) may result in delayed afterdepolarizations of the cell, which could serve as triggers for atrial arrhythmias [8]. We show here that the atria of patients with SDB undergo similar pathophysiological alterations. Enhanced SDB-dependent CaMKII activity results in increased SDB-dependent SR Ca leak, as measured by the frequency and characteristics of diastolic Ca sparks (Figure 3 and Figure S2). This is in accordance with increased CaMKII-dependent RyR2 phosphorylation in patients with SDB as previously 
shown [17]. Interestingly, in the present study the enhancement of SR Ca leak could be blocked by specific inhibition of CaMKII.

Continuous diastolic SR Ca leak may result in reduced SR Ca content. As a consequence, less $\mathrm{Ca}$ is available to be released during systole, resulting in impaired contractile function [49]. Indeed, we report here a decreased SR Ca content in atrial myocytes of patients with SDB, which could be increased again by CaMKII inhibition (Figure 4). This is in contrast to atrial myocytes isolated from patients with persistent atrial fibrillation, which showed no difference in SR Ca content [8,9], but resembles more closely the situation for failing ventricular myocytes [49]. The underlying mechanism may be SDB-specific and involve dysfunction of SR Ca reuptake despite a possible CaMKII-dependent increase in phospholamban phosphorylation. The latter may just not be sufficient to overcome the increased SR-Ca leak, a similar situation as observed in heart failure [49].

Nevertheless, the SDB-dependent remodeling of atrial Ca handling would greatly increase the propensity for atrial arrhythmias like atrial fibrillation. Moreover, the reduced systolic SR Ca release due to reduced SR Ca content could impair atrial contractility and contribute to the formation of blood clots. Reduced blood flow velocities, particularly in the left atrial appendage, have been shown to be associated with cardioembolic stroke. Accordingly, we found in the present study that the prevalence of AF and stroke was significantly increased in patients with SDB (Table 1), consistent with previous data from community samples $[11,50]$ and patients with chronic HF [51]. Interestingly, the prevalence of $\mathrm{AF}$ in the present $\mathrm{SDB}$ cohort was similar to the prevalence observed in patients with chronic HF [51].

\subsection{SDB-Dependent Pro-Arrhythmic Signaling Is Independent of Pre-Existing AF or HF}

As discussed above, CaMKII-dependent SR Ca leak has been observed in patients with AF $[8,9]$. Since atrial fibrillation alone might trigger pathophysiologic mechanisms independent of sleep apnea that would result in activation of CaMKII-dependent SR Ca leak, we aimed at excluding pre-existing AF as a potential confounder. First, multivariate linear regression indicated that the SDB-dependent increase in $\mathrm{CaSpF}$ was independent of pre-existing AF episodes, which is also consistent with previous findings [17]. Nevertheless, we have also studied patients in sinus rhythm separately in the present study. Interestingly, the SDB-dependent increase in CaMKII oxidation, activity and SR Ca leak was completely comparable to the entire patient cohort (Figure S3), indicating that pathophysiological factors triggered by SDB alone may be sufficient to oxidize and activate CaMKII, resulting in enhanced SR Ca leak.

In contrast to the clear association of SDB with CaMKII-dependent SR Ca leak, we found no significant correlation between magnitude of $\mathrm{CaSpF}$ and $\mathrm{AF}$ in the present study (Table 3). At first glance, this result appears to be counter-intuitive, since enhanced CaMKIIdependent SR Ca leak should also trigger episodes of AF. However, there are several explanations for this discrepancy. Firstly, we have not prospectively conducted Holter monitoring to identify patients with short lasting episodes of AF that depend on disturbed atrial $\mathrm{Ca}$ handling. The analysis of the prevalence of AF was solely based on retrospective evaluation of clinical information available at the time of surgery. Thus, paroxysmal AF may have been under-diagnosed in our patient cohort. Secondly, the development of AF is a complex process, since it involves early changes in Ca handling that predispose to atrial arrhythmias and is also accompanied by structural atrial remodeling, i.e., atrial fibrosis [52] This aligns with our finding that the proportion of patients with a dilated left atrium was significantly higher in the SDB group (Table 1). Structural atrial remodeling may result in a form of AF, which may be independent of pro-arrhythmic atrial Ca handling. Therefore, the small sample size, and the potential inclusion of patients with structural atrial remodeling, may have obscured any clear association between $\mathrm{AF}$ and $\mathrm{CaSpF}$ in our study. Nevertheless, our findings clearly point to the value of more intensive monitoring of SDB patients for episodes of AF, especially considering the concomitant risk of debilitating AF complications like stroke. 
In addition to pre-existing $\mathrm{AF}$, systolic contractile dysfunction of the left ventricle may result in atrial structural and electrical remodeling independent of SDB. In human HF, diastolic SR Ca leak has been shown to be increased in the left ventricle and to contribute to contractile dysfunction and ventricular arrhythmias [36]. Because SDB is an independent risk factor for the development of HF [53] and, in our cohort, LVEF was significantly impaired in patients with SDB (Table 1), it seems important to exclude systolic contractile dysfunction as a confounding factor. However, in the present study, SDB-related diastolic SR Ca leak was independent of impaired $\mathrm{EF}(\mathrm{EF}<50 \%)$ in univariate and multivariate regression models (Table 3), consistent with previous data showing that atrial SDB-dependent RyR2 phosphorylation was independent of HF [17]. This indicates that atrial alterations directly mediated by SDB have a stronger effect than a possible influence of impaired ventricular function.

\section{Conclusions}

SDB is highly prevalent in patients undergoing CABG surgery. It is associated with a dilated left atrium, a history of AF and a history of stroke. We show here that both atrial oxidation and activation of CaMKII are increased in patients with SDB, resulting in an increased CaMKII-dependent SR Ca leak, independent of clinical confounders. Because the CaMKII-dependent SR Ca leak may increase the risk of AF in patients with SDB, it may represent a potential pharmaceutical target for the prevention or treatment of AF, especially since clinical CaMKII inhibitors are currently under development.

Supplementary Materials: The following are available online at https:/ / www.mdpi.com/article / 10.3390/antiox11020331/s1: supplementary methods, Figure S1: CaSpF and caffeine-transient amplitude correlated with the severity of SDB, Figure S2: Patients with SDB showed increased diastolic Ca leak, Figure S3: SDB-dependent atrial remodeling was independent of AF, Table S1: Linear regression analyses for oxCaMKII/CaMKII, Table S2: Linear regression analyses between obstructive apnea index and calcium spark frequency, Table S3: Linear regression analyses between central apnea index and calcium spark frequency, Table S4: Linear regression analyses between Cheyne-Stokes respiration and calcium spark frequency.

Author Contributions: Conceptualization, S.W. (Stefan Wagner) and M.A.; methodology, M.A.D., S.R., S.M., A.B., M.D., K.K., J.M., S.K., M.T., S.L., B.F., D.C., S.W. (Sigrid Wittmann), J.B. and C.S.; software, M.A.D. and S.W. (Stefan Wagner); validation, S.W. and M.A.; formal analysis, M.A.D.; investigation, M.A.D. and M.A.; resources, L.S.M. and M.A.; data curation, S.W. (Stefan Wagner) and M.A.; writing—original draft preparation, M.A.D. and M.A.; writing-review and editing, S.W. (Stefan Wagner); visualization, M.A.D. and S.W. (Stefan Wagner); supervision, S.W. (Stefan Wagner); project administration, S.W. (Stefan Wagner); funding acquisition, S.W. (Stefan Wagner). All authors have read and agreed to the published version of the manuscript.

Funding: This research was funded by German Research Foundation (DFG) grant WA 2539/8-1 to S.W., grant SFB 1118 to J.B. and grant SFB 1350 grant (Project Number 387509280, TPA6) to S.W. and L.S.M. Research was also funded by the Faculty of Medicine, University of Regensburg, ReForM C program, to S.W. and L.S.M. It was funded by the DZHK (Deutsches Zentrum für Herz-KreislaufForschung, German Center for Cardiovascular Research) to S.W., J.B. and L.S.M. Research was also funded by a BMBF (German Ministry of Education and Research) grant to J.B.

Institutional Review Board Statement: The study was conducted according to the guidelines of the Declaration of Helsinki and approved by the Ethics Committees of the University of Göttingen (approval No. 14/09/11) and Regensburg, Germany.

Informed Consent Statement: Informed consent was obtained from all subjects involved in the study.

Data Availability Statement: The authors declare that all method protocols used in this study are available for any researcher upon request. To exclude the possibility of unintentionally sharing private patient information, patient data can only be made available after informed consent about a specific request has been given by each patient. 
Acknowledgments: We acknowledge the expert technical assistance of Thomas Sowa, Felicia Radtke, Timo Schulte and Kim Hansing. We thank Mark E. Anderson for kindly providing immune serum directed against oxidized M281/M282 (ox-CaMKII [20,43]) and D.M. Bers for kindly providing the rabbit polyclonal CaMKII antibody. We also thank Ben James for careful review of the manuscript.

Conflicts of Interest: The authors declare no conflict of interest.

\section{References}

1. European Heart Rhythm Association; European Association for Cardio-Thoracic Surgery; Camm, A.J.; Kirchhof, P.; Lip, G.Y.; Schotten, U.; Savelieva, I.; Ernst, S.; Van Gelder, I.C.; Al-Attar, N.; et al. Guidelines for the management of atrial fibrillation: The Task Force for the Management of Atrial Fibrillation of the European Society of Cardiology (ESC). Eur. Heart J. 2010, 31, 2369-2429. [CrossRef]

2. Go, A.S.; Hylek, E.M.; Phillips, K.A.; Chang, Y.; Henault, L.E.; Selby, J.V.; Singer, D.E. Prevalence of diagnosed atrial fibrillation in adults: National implications for rhythm management and stroke prevention: The AnTicoagulation and Risk Factors in Atrial Fibrillation (ATRIA) Study. JAMA 2001, 285, 2370-2375. [CrossRef] [PubMed]

3. Lavergne, F.; Morin, L.; Armitstead, J.; Benjafield, A.; Richards, G.; Woehrle, H. Atrial fibrillation and sleep-disordered breathing. J. Thorac. Dis. 2015, 7, E575-E584. [CrossRef]

4. Krijthe, B.P.; Kunst, A.; Benjamin, E.J.; Lip, G.Y.; Franco, O.H.; Hofman, A.; Witteman, J.C.; Stricker, B.H.; Heeringa, J. Projections on the number of individuals with atrial fibrillation in the European Union, from 2000 to 2060. Eur. Heart J. 2013, 34, $2746-2751$. [CrossRef] [PubMed]

5. Wakili, R.; Voigt, N.; Kaab, S.; Dobrev, D.; Nattel, S. Recent advances in the molecular pathophysiology of atrial fibrillation. J. Clin. Investig. 2011, 121, 2955-2968. [CrossRef] [PubMed]

6. Heijman, J.; Linz, D.; Schotten, U. Dynamics of Atrial Fibrillation Mechanisms and Comorbidities. Annu. Rev. Physiol. 2021, 83, 83-106. [CrossRef] [PubMed]

7. Voigt, N.; Heijman, J.; Wang, Q.; Chiang, D.Y.; Li, N.; Karck, M.; Wehrens, X.H.T.; Nattel, S.; Dobrev, D. Cellular and molecular mechanisms of atrial arrhythmogenesis in patients with paroxysmal atrial fibrillation. Circulation 2014, 129, 145-156. [CrossRef] [PubMed]

8. Voigt, N.; Li, N.; Wang, Q.; Wang, W.; Trafford, A.W.; Abu-Taha, I.; Sun, Q.; Wieland, T.; Ravens, U.; Nattel, S.; et al. Enhanced sarcoplasmic reticulum $\mathrm{Ca}^{2+}$ leak and increased $\mathrm{Na}^{+}-\mathrm{Ca}^{2+}$ exchanger function underlie delayed afterdepolarizations in patients with chronic atrial fibrillation. Circulation 2012, 125, 2059-2070. [CrossRef]

9. Neef, S.; Dybkova, N.; Sossalla, S.; Ort, K.R.; Fluschnik, N.; Neumann, K.; Seipelt, R.; Schondube, F.A.; Hasenfuss, G.; Maier, L.S. CaMKII-dependent diastolic SR $\mathrm{Ca}^{2+}$ leak and elevated diastolic $\mathrm{Ca}^{2+}$ levels in right atrial myocardium of patients with atrial fibrillation. Circ. Res. 2010, 106, 1134-1144. [CrossRef]

10. Gami, A.S.; Hodge, D.O.; Herges, R.M.; Olson, E.J.; Nykodym, J.; Kara, T.; Somers, V.K. Obstructive sleep apnea, obesity, and the risk of incident atrial fibrillation. J. Am. Coll. Cardiol. 2007, 49, 565-571. [CrossRef]

11. Arzt, M.; Young, T.; Finn, L.; Skatrud, J.B.; Bradley, T.D. Association of sleep-disordered breathing and the occurrence of stroke. Am. J. Respir. Crit. Care Med. 2005, 172, 1447-1451. [CrossRef]

12. Yaggi, H.K.; Concato, J.; Kernan, W.N.; Lichtman, J.H.; Brass, L.M.; Mohsenin, V. Obstructive sleep apnea as a risk factor for stroke and death. N. Engl. J. Med. 2005, 353, 2034-2041. [CrossRef]

13. Somers, V.K.; White, D.P.; Amin, R.; Abraham, W.T.; Costa, F.; Culebras, A.; Daniels, S.; Floras, J.S.; Hunt, C.E.; Olson, L.J.; et al. Sleep apnea and cardiovascular disease: An American Heart Association/American College of Cardiology Foundation Scientific Statement from the American Heart Association Council for High Blood Pressure Research Professional Education Committee, Council on Clinical Cardiology, Stroke Council, and Council on Cardiovascular Nursing. In collaboration with the National Heart, Lung, and Blood Institute National Center on Sleep Disorders Research (National Institutes of Health). Circulation 2008, 118, 1080-1111. [CrossRef]

14. Kanagala, R.; Murali, N.S.; Friedman, P.A.; Ammash, N.M.; Gersh, B.J.; Ballman, K.V.; Shamsuzzaman, A.S.; Somers, V.K. Obstructive sleep apnea and the recurrence of atrial fibrillation. Circulation 2003, 107, 2589-2594. [CrossRef] [PubMed]

15. Patel, D.; Mohanty, P.; Di Biase, L.; Shaheen, M.; Lewis, W.R.; Quan, K.; Cummings, J.E.; Wang, P.; Al-Ahmad, A.; Venkatraman, P.; et al. Safety and efficacy of pulmonary vein antral isolation in patients with obstructive sleep apnea: The impact of continuous positive airway pressure. Circ. Arrhythm. Electrophysiol. 2010, 3, 445-451. [CrossRef] [PubMed]

16. Traaen, G.M.; Aakerøy, L.; Hunt, T.E.; Øverland, B.; Bendz, C.; Sande, L.; Aakhus, S.; Fagerland, M.W.; Steinshamn, S.; Anfinsen, O.G.; et al. Effect of Continuous Positive Airway Pressure on Arrhythmia in Atrial Fibrillation and Sleep Apnea: A Randomized Controlled Trial. Am. J. Respir. Crit. Care Med. 2021, 204, 573-582. [CrossRef] [PubMed]

17. Lebek, S.; Pichler, K.; Reuthner, K.; Trum, M.; Tafelmeier, M.; Mustroph, J.; Camboni, D.; Rupprecht, L.; Schmid, C.; Maier, L.S.; et al. Enhanced CaMKII-Dependent Late I(Na) Induces Atrial Proarrhythmic Activity in Patients with SleepDisordered Breathing. Circ. Res. 2020, 126, 603-615. [CrossRef]

18. Lavie, L. Oxidative stress in obstructive sleep apnea and intermittent hypoxia—Revisited-The bad ugly and good: Implications to the heart and brain. Sleep Med. Rev. 2015, 20, 27-45. [CrossRef] [PubMed] 
19. Linz, D.; Hohl, M.; Nickel, A.; Mahfoud, F.; Wagner, M.; Ewen, S.; Schotten, U.; Maack, C.; Wirth, K.; Bohm, M. Effect of renal denervation on neurohumoral activation triggering atrial fibrillation in obstructive sleep apnea. Hypertension 2013, 62, 767-774. [CrossRef] [PubMed]

20. Erickson, J.R.; Joiner, M.L.; Guan, X.; Kutschke, W.; Yang, J.; Oddis, C.V.; Bartlett, R.K.; Lowe, J.S.; O’Donnell, S.E.; Aykin-Burns, N.; et al. A dynamic pathway for calcium-independent activation of CaMKII by methionine oxidation. Cell 2008, 133, 462-474. [CrossRef] [PubMed]

21. Purohit, A.; Rokita, A.G.; Guan, X.; Chen, B.; Koval, O.M.; Voigt, N.; Neef, S.; Sowa, T.; Gao, Z.; Luczak, E.D.; et al. Oxidized $\mathrm{Ca}^{2+} /$ calmodulin-dependent protein kinase II triggers atrial fibrillation. Circulation 2013, 128, 1748-1757. [CrossRef] [PubMed]

22. Lebek, S.; PLoSsl, A.; Baier, M.; Mustroph, J.; Tarnowski, D.; Lucht, C.M.; Schopka, S.; Florchinger, B.; Schmid, C.; Zausig, Y.; et al. The novel CaMKII inhibitor GS-680 reduces diastolic SR Ca leak and prevents CaMKII-dependent pro-arrhythmic activity. J. Mol. Cell Cardiol. 2018, 118, 159-168. [CrossRef] [PubMed]

23. Chen, H.; Lowe, A.A.; Bai, Y.; Hamilton, P.; Fleetham, J.A.; Almeida, F.R. Evaluation of a portable recording device (ApneaLink) for case selection of obstructive sleep apnea. Sleep Breath. Schlaf Atm. 2009, 13, 213-219. [CrossRef]

24. Clark, A.L.; Crabbe, S.; Aziz, A.; Reddy, P.; Greenstone, M. Use of a screening tool for detection of sleep-disordered breathing. J. Laryngol. Otol. 2009, 123, 746-749. [CrossRef]

25. Erman, M.K.; Stewart, D.; Einhorn, D.; Gordon, N.; Casal, E. Validation of the ApneaLink for the screening of sleep apnea: A novel and simple single-channel recording device. J. Clin. Sleep Med. JCSM Off. Publ. Am. Acad. Sleep Med. 2007, 3, 387-392. [CrossRef]

26. Ng, S.S.; Chan, T.O.; To, K.W.; Ngai, J.; Tung, A.; Ko, F.W.; Hui, D.S. Validation of a portable recording device (ApneaLink) for identifying patients with suspected obstructive sleep apnoea syndrome. Intern. Med. J. 2009, 39, 757-762. [CrossRef]

27. Ragette, R.; Wang, Y.; Weinreich, G.; Teschler, H. Diagnostic performance of single airflow channel recording (ApneaLink) in home diagnosis of sleep apnea. Sleep Breath. Schlaf Atm. 2010, 14, 109-114. [CrossRef]

28. Wang, Y.; Teschler, T.; Weinreich, G.; Hess, S.; Wessendorf, T.E.; Teschler, H. Validation of microMESAM as screening device for sleep disordered breathing. Pneumol. (Stuttg. Ger.) 2003, 57, 734-740. [CrossRef]

29. Arzt, M.; Woehrle, H.; Oldenburg, O.; Graml, A.; Suling, A.; Erdmann, E.; Teschler, H.; Wegscheider, K.; Schla, H.F.I. Prevalence and Predictors of Sleep-Disordered Breathing in Patients with Stable Chronic Heart Failure: The SchlaHF Registry. JACC Heart Fail. 2016, 4, 116-125. [CrossRef] [PubMed]

30. Tafelmeier, M.; Weizenegger, T.; Ripfel, S.; Fauser, M.; Floerchinger, B.; Camboni, D.; Zausig, Y.; Wittmann, S.; Drzymalski, M.A.; Zeman, F.; et al. Postoperative complications after elective coronary artery bypass grafting surgery in patients with sleep-disordered breathing. Clin. Res. Cardiol. Off. J. Ger. Card. Soc. 2018, 107, 1148-1159. [CrossRef] [PubMed]

31. Kreusser, M.M.; Lehmann, L.H.; Keranov, S.; Hoting, M.O.; Oehl, U.; Kohlhaas, M.; Reil, J.C.; Neumann, K.; Schneider, M.D.; Hill, J.A.; et al. Cardiac CaM Kinase II genes delta and gamma contribute to adverse remodeling but redundantly inhibit calcineurin-induced myocardial hypertrophy. Circulation 2014, 130, 1262-1273. [CrossRef] [PubMed]

32. Voigt, N.; Zhou, X.B.; Dobrev, D. Isolation of human atrial myocytes for simultaneous measurements of Ca ${ }^{2+}$ transients and membrane currents. J. Vis. Exp. JoVE 2013, 77, e50235. [CrossRef]

33. Wagner, S.; Dantz, C.; Flebbe, H.; Azizian, A.; Sag, C.M.; Engels, S.; Mollencamp, J.; Dybkova, N.; Islam, T.; Shah, A.M.; et al NADPH oxidase 2 mediates angiotensin II-dependent cellular arrhythmias via PKA and CaMKII. J. Mol. Cell Cardiol. 2014, 75, 206-215. [CrossRef]

34. Wagner, S.; Dybkova, N.; Rasenack, E.C.; Jacobshagen, C.; Fabritz, L.; Kirchhof, P.; Maier, S.K.; Zhang, T.; Hasenfuss, G.; Brown, J.H.; et al. $\mathrm{Ca}^{2+}$ /calmodulin-dependent protein kinase II regulates cardiac $\mathrm{Na}^{+}$channels. J. Clin. Investig. 2006, 116, 3127-3138. [CrossRef]

35. Mustroph, J.; Wagemann, O.; Lucht, C.M.; Trum, M.; Hammer, K.P.; Sag, C.M.; Lebek, S.; Tarnowski, D.; Reinders, J.; Perbellini, F.; et al. Empagliflozin reduces Ca/calmodulin-dependent kinase II activity in isolated ventricular cardiomyocytes. ESC Heart Fail. 2018, 5, 642-648. [CrossRef]

36. Fischer, T.H.; Herting, J.; Tirilomis, T.; Renner, A.; Neef, S.; Toischer, K.; Ellenberger, D.; Forster, A.; Schmitto, J.D.; Gummert, J.; et al. $\mathrm{Ca}^{2+} /$ calmodulin-dependent protein kinase II and protein kinase A differentially regulate sarcoplasmic reticulum $\mathrm{Ca}^{2+}$ leak in human cardiac pathology. Circulation 2013, 128, 970-981. [CrossRef]

37. Sossalla, S.; Fluschnik, N.; Schotola, H.; Ort, K.R.; Neef, S.; Schulte, T.; Wittkopper, K.; Renner, A.; Schmitto, J.D.; Gummert, J.; et al Inhibition of elevated $\mathrm{Ca}^{2+} /$ calmodulin-dependent protein kinase II improves contractility in human failing myocardium. Circ. Res. 2010, 107, 1150-1161. [CrossRef]

38. Wagner, S.; Ruff, H.M.; Weber, S.L.; Bellmann, S.; Sowa, T.; Schulte, T.; Anderson, M.E.; Grandi, E.; Bers, D.M.; Backs, J.; et al Reactive oxygen species-activated $\mathrm{Ca} /$ calmodulin kinase IIdelta is required for late $\mathrm{I}(\mathrm{Na})$ augmentation leading to cellular $\mathrm{Na}$ and Ca overload. Circ. Res. 2011, 108, 555-565. [CrossRef]

39. Erickson, J.R.; Patel, R.; Ferguson, A.; Bossuyt, J.; Bers, D.M. Fluorescence resonance energy transfer-based sensor Camui provides new insight into mechanisms of calcium/calmodulin-dependent protein kinase II activation in intact cardiomyocytes. Circ. Res. 2011, 109, 729-738. [CrossRef] [PubMed]

40. Luo, M.; Guan, X.; Luczak, E.D.; Lang, D.; Kutschke, W.; Gao, Z.; Yang, J.; Glynn, P.; Sossalla, S.; Swaminathan, P.D.; et al. Diabetes increases mortality after myocardial infarction by oxidizing CaMKII. J. Clin. Investig. 2013, 123, 1262-1274. [CrossRef] 
41. Dyugovskaya, L.; Lavie, P.; Lavie, L. Increased adhesion molecules expression and production of reactive oxygen species in leukocytes of sleep apnea patients. Am. J. Respir. Crit. Care Med. 2002, 165, 934-939. [CrossRef] [PubMed]

42. Schulz, R.; Mahmoudi, S.; Hattar, K.; Sibelius, U.; Olschewski, H.; Mayer, K.; Seeger, W.; Grimminger, F. Enhanced release of superoxide from polymorphonuclear neutrophils in obstructive sleep apnea. Impact of continuous positive airway pressure therapy. Am. J. Respir. Crit. Care Med. 2000, 162, 566-570. [CrossRef]

43. Ai, X.; Curran, J.W.; Shannon, T.R.; Bers, D.M.; Pogwizd, S.M. Ca ${ }^{2+} /$ calmodulin-dependent protein kinase modulates cardiac ryanodine receptor phosphorylation and sarcoplasmic reticulum $\mathrm{Ca}^{2+}$ leak in heart failure. Circ. Res. 2005, 97, 1314-1322. [CrossRef] [PubMed]

44. Wagner, S.; Rokita, A.G.; Anderson, M.E.; Maier, L.S. Redox regulation of sodium and calcium handling. Antioxid. Redox Signal. 2013, 18, 1063-1077. [CrossRef] [PubMed]

45. Lymperopoulos, A.; Rengo, G.; Koch, W.J. Adrenergic nervous system in heart failure: Pathophysiology and therapy. Circ. Res. 2013, 113, 739-753. [CrossRef]

46. Workman, A.J. Cardiac adrenergic control and atrial fibrillation. Naunyn Schmiedebergs Arch. Pharmacol. 2010, 381, 235-249. [CrossRef]

47. Toischer, K.; Rokita, A.G.; Unsold, B.; Zhu, W.; Kararigas, G.; Sossalla, S.; Reuter, S.P.; Becker, A.; Teucher, N.; Seidler, T.; et al Differential cardiac remodeling in preload versus afterload. Circulation 2010, 122, 993-1003. [CrossRef]

48. Wehrens, X.H.; Lehnart, S.E.; Reiken, S.R.; Marks, A.R. $\mathrm{Ca}^{2+} /$ calmodulin-dependent protein kinase II phosphorylation regulates the cardiac ryanodine receptor. Circ. Res. 2004, 94, e61-e70. [CrossRef] [PubMed]

49. Maier, L.S.; Zhang, T.; Chen, L.; DeSantiago, J.; Brown, J.H.; Bers, D.M. Transgenic CaMKIIdeltaC overexpression uniquely alters cardiac myocyte $\mathrm{Ca}^{2+}$ handling: Reduced SR Ca ${ }^{2+}$ load and activated SR Ca ${ }^{2+}$ release. Circ. Res. 2003, 92, 904-911. [CrossRef]

50. Mehra, R.; Benjamin, E.J.; Shahar, E.; Gottlieb, D.J.; Nawabit, R.; Kirchner, H.L.; Sahadevan, J.; Redline, S.; Sleep Heart Health Study. Association of nocturnal arrhythmias with sleep-disordered breathing: The Sleep Heart Health Study. Am. J. Respir. Crit. Care Med. 2006, 173, 910-916. [CrossRef]

51. Arzt, M.; Oldenburg, O.; Graml, A.; Erdmann, E.; Teschler, H.; Wegscheider, K.; Suling, A.; Woehrle, H.; Schla, H.F.I. Phenotyping of Sleep-Disordered Breathing in Patients with Chronic Heart Failure with Reduced Ejection Fraction-the SchlaHF Registry. J. Am. Heart Assoc. 2017, 6, e005899. [CrossRef] [PubMed]

52. Frustaci, A.; Chimenti, C.; Bellocci, F.; Morgante, E.; Russo, M.A.; Maseri, A. Histological substrate of atrial biopsies in patients with lone atrial fibrillation. Circulation 1997, 96, 1180-1184. [CrossRef] [PubMed]

53. Shahar, E.; Whitney, C.W.; Redline, S.; Lee, E.T.; Newman, A.B.; Nieto, F.J.; O'Connor, G.T.; Boland, L.L.; Schwartz, J.E.; Samet, J.M. Sleep-disordered breathing and cardiovascular disease: Cross-sectional results of the Sleep Heart Health Study. Am. J. Respir. Crit. Care Med. 2001, 163, 19-25. [CrossRef] [PubMed] 